\title{
Ativador do plasminogênio tecidual e gás intravítreo no tratamento da síndrome de Terson: relato de caso
}

\author{
Tissue plasminogen activator and intravitreal gas for the treatment \\ of Terson's syndrome: case report
}

Pedro Durães Serracarbassa ${ }^{1}$

Luciana Duarte Rodrigues ${ }^{2}$

Juliana Ribeiro Rodrigues ${ }^{3}$

\section{RESUMO}

Relata-se o caso de um paciente de 35 anos de idade, sexo masculino, com história de trauma cranioencefálico, que evoluiu com hemorragia prémacular da síndrome de Terson no olho esquerdo. Após 45 dias de conduta expectante, sem resolução da hemorragia, foi realizada injeção intravítrea de gás hexafluoreto de enxofre e tPA, evoluindo com absorção quase completa da hemorragia após uma semana e considerável melhora da acuidade visual. Descreve-se também aspectos importantes da síndrome de Terson e da injeção intravítrea de gás e tPA por meio de revisão da literatura.

Descritores: Hemorragia subaracnóidea/etiologia; Traumatismos craniocerebrais/complicações; Hemorragia retiniana/terapia; Ativador de plasminogênio tecidual/uso terapêutico; Síndrome; Injeções; Hexafluoreto de enxofre/administração \& dosagem; Relatos de casos [Tipo de publicação]

\section{INTRODUÇÃO}

A síndrome de Terson é descrita como hemorragia vítrea secundária a hemorragia subaracnoidea ou subdural. O sangue pode estar localizado abaixo da membrana limitante interna da retina ou no espaço sub-hialoideo. A hemorragia intraocular tem sido atribuída ao rápido aumento da pressão venosa ou intracraniana, que rompe os capilares peri-papilares ou causa compressão da veia central da retina ${ }^{(1)}$. O prognóstico visual na síndrome de Terson é geralmente bom, com reabsorção espontânea do sangue. Ocasionalmente, resultados visuais ruins ocorrem por não absorção da hemorragia vítrea, dobras da retina, formação de membrana epirretiniana, alterações pigmentares da mácula, vitreorretinopatia proliferativa e atrofia óptica $^{(2)}$. Nos casos de hemorragia bilateral ou hemorragia vítrea de longa duração está indicada a vitrectomia ${ }^{(3)}$. Fotodisrrupção com Nd:YAG laser e laser de argônio foram propostos como métodos alternativos de tratamento para hemorragias pré-retinianas ${ }^{(4-5)}$. Este estudo apresenta um caso de hemorragia pré-macular, secundária a hemorragia intracraniana, tratada com gás hexafluoreto de enxofre e ativador do plasminogênio tecidual (tPA) intravítreos. Pela primeira vez na literatura, a associação de tPA e gás hexafluoreto de enxofre intravítreos é utilizada para o tratamento de hemorragia pré-macular na síndrome de Terson.

\section{RELATO DE CASO}

Paciente do sexo masculino, 35 anos, com história de perda visual súbita no olho esquerdo há 15 dias, quando sofreu trauma cranioencefálico. Apre- 
sentava paralisia facial direita e a tomografia computadorizada mostrava hemorragia intracraniana no lobo temporal esquerdo. Não havia antecedentes oftalmológicos relevantes até a data do trauma. A acuidade visual era 20/40 no olho direito e conta dedos no olho esquerdo. A motilidade e as pressões oculares eram normais. $\mathrm{O}$ fechamento palpebral era incompleto à direita. A inspeção do segmento anterior era normal.

A oftalmoscopia revelou papiledema bilateral e hemorragia pré-macular no olho esquerdo (Figura 1). Quarenta e cinco dias após a primeira consulta, os achados oftalmológicos mostravam melhora do papiledema bilateral e persistência da hemorragia pré-macular no olho esquerdo. A acuidade visual era 20/20 no olho direito e conta dedos no olho esquerdo. Foi realizada injeção intravítrea de gás hexafluoreto de enxofre e tPA no olho esquerdo. A injeção foi realizada com o paciente sob anestesia retrobulbar com lidocaína a $2 \%$. Foi aplicada Betadine ${ }^{\circledR}$ nas pálpebras e o olho foi irrigado com Betadine ${ }^{\circledR}$ a $5 \%$. Vinte e cinco microgramas de solução de tPA (Ophthalmos, São Paulo) em $0,1 \mathrm{ml}$ foram aspiradas em seringa de tuberculina e injetadas via pars plana, a 4,0 mm do limbo, no quadrante temporal superior, através de uma agulha calibre 13 x 7 . Após paracentese da câmara anterior, 0,5 ml de gás hexafluoreto de enxofre (White Martins) a $100 \%$ foi injetado na cavidade vítrea. O paciente foi instruído a manter a pronoposição por 72 horas.

Um dia após a injeção, a hemorragia pré-macular não mostrou alteração. No terceiro dia, o coágulo diminuiu de tamanho e adquiriu cor amarelada. Uma semana após a injeção, a hemorragia pré-macular estava quase completamente absorvida, restando apenas traços de hemorragia abaixo da fóvea. Foi observada uma membrana epimacular (Figura 2). A acuidade visual era 20/20 no olho direito e 20/50 no olho esquerdo.

Um mês depois, os traços de hemorragia abaixo da fóvea e a membrana epirretiniana persistiram. A acuidade visual e a oftalmoscopia se mantiveram inalteradas seis meses depois.

\section{DISCUSSÃO}

A síndrome de Terson apresenta, em geral, bom prognóstico. A recuperação visual ocorre na maioria dos pacientes, com reabsorção espontânea da hemorragia vítrea, sub-hialoidea ou submembrana limitante interna. Maus resultados se devem a não absorção da hemorragia vítrea, dobras de retina, membrana epirretiniana, alterações pigmentares da mácula, vitreorretinopatia proliferativa e atrofia óptica ${ }^{(2)}$. A vitrectomia está indicada nos casos de hemorragia bilateral ou hemorragia vítrea de longa duração ${ }^{(3)}$. O intervalo de tempo entre a hemorragia intraocular e a vitrectomia é incerto. Geralmente, a vitrectomia é indicada nas opacidades unilaterais que não regridem entre três a seis meses após o evento inicial. Entretanto, complicações como membrana epirretiniana, retinopatia vitreoproliferativa e alterações pigmentares da mácula, são observadas em alguns pacientes após absorção espontânea do sangue ${ }^{(2)}$. A vitrectomia precoce tem sido indicada por alguns autores para prevenir estas complicações ${ }^{(3)}$.

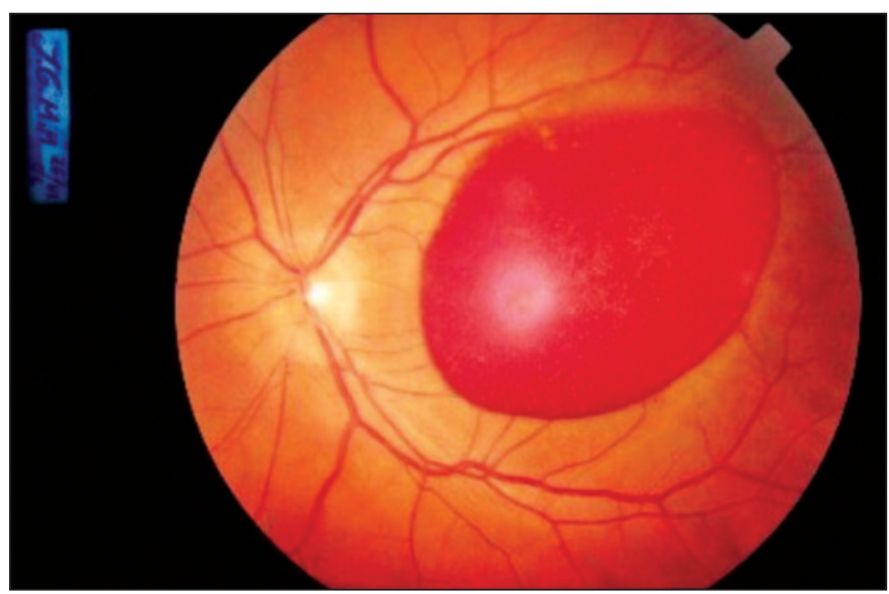

Figura 1 - Fotografia do polo posterior do olho esquerdo antes do tratamento, mostrando hemorragia pré-retiniana envolvendo a mácula e edema do nervo óptico

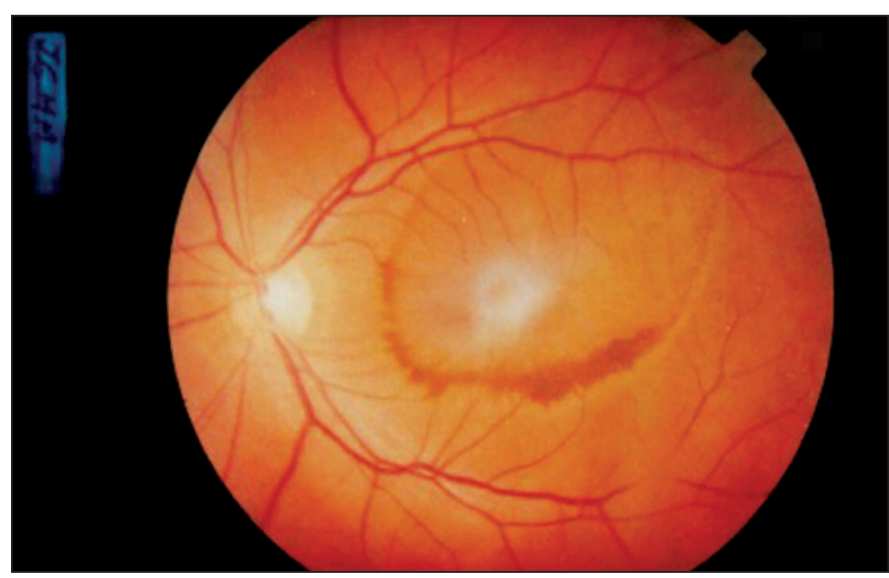

Figura 2 - Fotografia do polo posterior 7 dias após tratamento, mostrando reabsorção da hemorragia pré-retiniana e membrana epirretiniana

Apesar dos bons resultados da vitrectomia na síndrome de Terson, complicações como descolamento de retina, diálise de retina, roturas retinianas e membranas epirretinianas são rela$\operatorname{tadas}^{(3)}$. Métodos alternativos de tratamento da hemorragia intraocular são descritos. Drenagem da hemorragia pré-retiniana com laser de $\operatorname{argônio~}^{(4)}$ ou Nd: YAG laser ${ }^{(5)}$ no vítreo são viáveis, porém, complicações como buraco macular e descolamento de retina foram observadas ${ }^{(5)}$.

$\mathrm{O}$ ativador do plasminogênio tecidual é um agente trombolítico que, na presença de fibrina, ativa o plasminogênio em plasmina. A injeção intraocular de tPA tem sido usada para o tratamento da hemorragia vítrea, formação de fibrina pós-vitrectomia, hemorragia submacular (doença macular relacionada à idade; neovascularização de coróide idiopática; trauma; retinopatia de Valsalva.), doenças vasculares oclusivas da retina, endoftalmite e hemorragia supracoroidea ${ }^{(6)}$. A associação de tPA e gás perfluoropropano intraocular mostrou bons resultados visuais e anatômicos no tratamento da hemorragia submacular secundária a membrana neovas- 
cular de coróide, macroaneurisma roto e pós-cirurgia de descolamento de retina ${ }^{(7-8)}$.

O presente relato de caso trata-se de uma hemorragia préretiniana e macular que em muito se assemelha às alterações fundoscópicas encontradas na retinopatia de Valsalva, entretanto, a história pregressa de trauma craniano contuso; hipertensão e hemorragia intracraniana sustenta o diagnóstico de síndrome de Terson que evoluiu com resultado visual e anatômico excelentes após sete dias da injeção de tPA e gás intravítreos. Não ocorreram complicações associadas às injeções intraoculares. Presumimos que o bom resultado esteja relacionado ao tratamento, mas a hipótese de absorção espontânea não pode ser afastada. A acuidade visual final poderia ser ainda melhor se não houvesse a formação da membrana epimacular, que pode estar associada a edema macular. A presença de membrana epirretiniana, após a resolução da hemorragia pré-macular, sugere que uma intervenção precoce seria preferível neste caso.

Apesar dos bons resultados do tPA e gás intravítreos, complicações raras como descolamento de retina, catarata, endoftalmite e hemorragia vítrea são relatadas ${ }^{(6-8)}$. Questões relacionadas a toxicidade retiniana e dose ideal de tPA, penetração sub-retiniana de tPA e uso isolado do gás intravítreo têm sido levantadas ${ }^{(9)}$. Estudo descreve alterações retinianas anatômicas e funcionais após o uso do tPA em humano semelhantes às encontradas em modelos animais, sugerindo toxicidade retiniana ${ }^{(9)}$. A dose usada no presente caso, $25 \mu \mathrm{g}$, é considerada segura e provavelmente não tem relação com a acuidade visual final. Estudos demonstraram que doses entre 50 e $100 \mu \mathrm{g}$ são tóxicas para a retina humana ${ }^{(9)}$. A penetração sub-retiniana de tPA é teoricamente possível, por causa de suas propriedades similares à albumina. $\mathrm{O}$ peso molecular da albumina é responsável por seu transporte passivo através da retina. Entretanto, estudos experimentais foram incapazes de demonstrar partículas de tPA no espaço sub-retiniano ${ }^{(10)}$. Autores sugerem que o tPA possa atravessar a retina por pequenos buracos na membrana limitante interna ${ }^{(10)}$. A dose ideal de tPA intravítreo é controversa. É descrita reabsorção do sangue com doses de 25, 50, 75 e $100 \mu g^{(8)}$. Provavelmente, a dose ideal tem relação com a quantidade de fibrina no coágulo. $\mathrm{O}$ uso isolado de gás intravítreo no tratamento da hemorragia sub-retiniana também foi descrito ${ }^{(7)}$. O efeito mecânico do gás seria a causa principal da reabsorção do sangue ${ }^{(7)}$. Entretanto, no presente caso, a rápida absorção da hemorragia pode ser explicada pela ação sinérgica entre tPA e gás: a propriedade fibrinolítica do tPA teria facilitado a dissolução do coágulo e o gás teria proporcionado uma compressão mecânica sobre a hemorragia que encontrava-se em estado anticoagulado. A associação do gás hexafluoreto de enxofre e do tPA intravítreo no tratamento da hemorragia pré-retiniana na síndrome de Terson surge como um procedimento seguro, que oferece rápida melhora visual. Estudos futuros são necessários para provar a eficácia desta associação.

\section{ABSTRACT}

The case of a 35 year-old male patient is reported. The patient had a clinical history of craniocerebral trauma and premacular hemorrhage of Terson syndrome in the left eye. After waiting for 45 days, without hemorrhage resolution, the patient received an intravitreal injection of sulfur hexafluoride gas and tPA; an almost complete hemorrhage absorption occurred after a week as well as a considerable improvement of visual acuity. In the report, relevant aspects of Terson syndrome and of intravitreal injection of gas and tPA are also described through a literature review.

Keywords: Subarachnoid hemorrhage/etiology; Craniocerebral trauma/complications; Retina hemorrhage/therapy; Tissue plasminogen activator/therapeutic use; Syndrome; Injections; Sulfur hexafluoride/administration \& dosage; Case reports [Publication type]

\section{REFERÊNCIAS}

1. Ogawa T, Kitaoka T, Dake Y, Amemiya T. Terson syndrome: a case report suggesting the mechanism of vitreous hemorrhage. Opthalmology. 2001;108(9): 1654-6.

2. Augsten R, Königsdörffer E, Strobel J. Surgical approach in Terson syndrome: vitreous and retinal findings. Eur J Ophthalmol. 2000;10(4):293-6.

3. Gnanaraj L, Tyagi AK, Cottrell DG, Fetherston TJ, Richardson J, Stannard KP, Inglesby DV. Referral delay and ocular surgical outcome in Terson syndrome. Retina. 2000;20(4):374-7.

4. Osoba Y, Talbot M. Indirect delivery of argon laser to disperse premacular hemorrhage in a recumbent visually handicapped patient with Terson's syndrome. Eye. 2000;14 Pt 5:800-2.

5. Ulbig MW, Mangouritsas G, Rothbacher HH, Hamilton AM, McHugh JD. Long-term results after drainage of premacular subhyaloid hemorrhage into the vitreous with a pulsed Nd:YAG laser. Arch Ophthalmol. 1998;116(11):1465-9.

6. Ratanasukon M, Kittantong A. Results of intravitreal tissue plasminogen activator and expansile gas injection for submacular haemorrhage in Thais. Eye. 2005;19(12):1328-32.

7. Yang PM, Kuo HK, Kao ML, Chen YJ, Tsai HH. Pneumatic displacement of a dense submacular hemorrhage with or without tissue plasminogen activator. Chang Gung Med J. 2005;28(12):852-9.

8. Hattenbach LO, Klais C, Koch FH, Gümbel HO. Intravitreous injection of tissue plasminogen activator and gas in the treatment of submacular hemorrhage under various conditions. Ophthalmology. 2001;108(8):1485-92. Comment in: Ophthalmology. 2002;109(5):824; author reply 825.

9. Chen SN, Yang TC, Ho CL, Kuo YH, Yip Y, Chao AN. Retinal toxicity of intravitreal tissue plasminogen activator: case report and literature review. Ophthalmology. 2003;110(4):704-8.

10. Kamei M, Misono K, Lewis H. A study of the ability of tissue plasminogen activator to diffuse into the subretinal space after intravitreal injection in rabbits. Am J Ophthalmol. 1999;128(6):739-46. 